\title{
Kariyer Hedefi Geribildirim Ölçeği'nin (KHGÖ) Türkçeye Uyarlanması: Geçerlik ve Güvenirlik Çalışması
}

\section{Adaptation of Career Goal Feedback Scale to Turkish: Validity and Reliability Study}

Ozan KORKMAZ*

Received: 12 July 2018
Research Article

\begin{abstract}
In this study, it was aimed to adapt the Career Goal Feedback Scale (CGFS) to Turkish. The research was conducted on 1.077 students from two different universities and five different high schools. As a result of confirmatory factor analysis conducted to test the validity of the structure of the scale, it was seen that the original form consisting of six dimensions and 24 items which was adapted to the Turkish was confirmed. The Cronbach Alpha internal consistency coefficient of the scale was found to be .88 in the data group of the university students and .85 in the data group of the high school students. Test-retest correlation coefficient of the scale was calculated as .77 in the data group of university students and .73 in the data group high school students. Correlations between the English and Turkish forms of the CGFS were found to be positively and highly correlated. The item-total correlations of the scale were found to vary between .36 and .62 for university students and between .31 and .56 for high school students. In the analyses made for the concurrent validity of the scale, it was determined that the CGFS had a positive and high correlation with the Career Stress Scale and negative and medium correlation with the General Self-Efficacy Scale. The research findings provide important evidence that the six-factor original structure of the CGFS is validated and can be used as a valid and reliable measurement tool for assessing feedback on career goals.
\end{abstract}

Keywords: career goal feedback, career development processes, career counseling.

ÖZ: Bu çalışmada Kariyer Hedefi Geribildirim Ölçeğinin (KHGÖ) Türkçeye uyarlanması amaçlanmıştır. Araştırma, iki farklı üniversite ve beş farklı lisede öğrenim gören toplam 1.077 öğrenci üzerinde yapılmıştır. Ölçeğin yapı geçerliğini test etmek için yapılan doğrulayıcı faktör analizi sonucunda, Türkçeye uyarlanan ölçeğin altı boyutlu ve 24 maddeden oluşan özgün formunun doğrulandığı görülmüştür. Ölçeğin Cronbach Alpha iç tutarlık katsayıs1 üniversite öğrencilerine ait veri grubunda .88 , lise öğrencilerine ait veri grubunda .85 olarak bulunmuştur. Ölçeğin test-tekrar test korelasyon katsayıs1 üniversite öğrencilerine ait veri grubunda .77 , lise öğrencilerine ait veri grubunda ise .73 olarak hesaplanmıştır. KHGÖ’nün uygulanan İngilizce ve Türkçe formları arasındaki korelasyonun pozitif ve yüksek düzeyde ilişkili olduğu görülmüştür. Ölçeğin madde-toplam korelasyonları üniversite öğrencilerinde .36 ile .62, lise öğrencilerinde ise .31 ile .56 arasında değiştiği bulunmuştur. Ölçeğin uyum geçerliği için yapılan analizlerde KHGÖ’nün Kariyer Stresi Ölçeği ile pozitif ve yüksek düzeyde, Genel Öz-Yeterlik Ölçeği ile negatif ve orta düzeyde ilişkilere sahip olduğu belirlenmiştir. Araştırma bulguları, KHGÖ’nün altı faktörlü orijinal yapısının doğrulandığına ve kariyer hedeflerine ilişkin geribildirimleri değerlendirmede geçerli ve güvenilir bir ölçüm aracı olarak kullanılabileceğine ilişkin önemli kanıtlar sağlamaktadır.

Anahtar kelimeler: kariyer hedefi geribildirimi, kariyer gelişim süreçleri, kariyer danışmanlığı.

\footnotetext{
* Corresponding Author: PhD Candidate, Çukurova University, Adana, Turkey, pd.ozankorkmaz@gmail.com, https://orcid.org/0000-0002-0541-200X

Asst. Prof. Dr., Çukurova University, Adana, Turkey, okirdok@gmail.com, https://orcid.org/0000-0003-40762619
}

Citation Information

Korkmaz, O. \& Kırdök, O. (2018). Kariyer Hedefi Geribildirim Ölçeğinin (KHGÖ) Türkçeye uyarlanması: Geçerlik ve güvenirlik çalışması. Kuramsal Eğitimbilim Dergisi [Journal of Theoretical Educational Science], 12(2), 494-510. 


\section{Giriş}

Kariyer, bireyin hayat boyu devam eden uğraşlarını ve yaşamları boyunca oynadıkları rolleri ifade eden bir kavramdır. Yaygın olarak lise ya da üniversite yıllarını kapsayan kariyer belirleme ve karar verme süreci, yaşamın geri kalanını da ilgilendirdiği için üzerinde durulması gereken bir konudur (Sharf, 2017). Kariyer karar verme sürecinde mesleğini belirleyen birey bir kariyer hedefi oluşturmuş olur. $\mathrm{Bu}$ hedefe ulaşmak için yapması gereken birçok faaliyet ve görev vardır. Kariyer hedefi, bireyin gelecekteki çalışma yaşamında nerde olmak istediğidir, yani bireyin çalışma dünyasındaki rotası olduğu söylenebilir (Özden, 2007). Böylece bir kariyer hedefi olan birey, bu hedefe ulaşmasına yardımcı olacak olası fırsatlarla ilgili farkındalığa sahip olur, daha disiplinli ve sorumlu bir şekilde hareket eder (Zajas \& Zajas, 1994) ayrica daha fazla motivasyon gösterir (Greenhaus ve diğerleri, 1995). Locke ve Latham'a (2006) göre belirli hedefleri olan bireyler olmayanlara göre görevlerinde daha yüksek düzeyde performans göstermektedirler. Bir hedefe yönelik ilerleme geribildirim gerektirir. Çünkü geribildirim hedef doğrultusunda kat edilen veya kat edilmesi gereken aşamalar hakkında bilgi verir. Hedefe yönelik faaliyetleri gerektiğinde düzeltmeyi ve düzenlemeyi sağlar. Geribildirimin eksikliği bireyin bu gerekli düzeltmeleri yapması için bilgi sağlanamayacağı için hedefe ulaşmayı zorlaştıracak veya engelleyecektir (Locke \& Latham, 2002). Bunun yanı sira Bandura (1991) geribildirimin bireyin motivasyonu üzerinde düzenleyici etkisi olduğunu savunmuş ve bireylerin hedeflerine ilişkin geribildirim aldıklarında performanslarının etkililiğinin arttığını ifade etmiştir. Geribildirim öğrenme ve başarı üzerinde en güçlü etkilerden biridir. Genel olarak bilgi ve beceri sağlamayı ya da belirli tutumları geliştirmeyi amaçlayan açıklamalardan sonra meydana gelir (Hattie \& Timperley, 2007). Bireyin kariyer gelişiminde geribildirimlerin de etkili olabileceği söylenebilir. Çünkü geribildirim bir kişinin performansı ya da öğrenmesi ile ilgili bilgiler içermektedir.

Hu, Creed \& Hood'a (2017) göre kariyer hedefi geri bildirimi; kariyer hedefinin uygunluğu, hedefe yönelik ilerlemenin yeterliliği ve hedeflere ulaşmak için hangi değişikliklerin yapılması gerektiği hakkında bilgi sağlama olarak tanımlanmaktadır. Kariyerlerini belirleme döneminde olan ergen ve genç yetişkinler, geribildirimler sayesinde kariyer hedefleriyle ilgili genel durumu ve bu hedefleriyle ilgili tutarlı hareket edip etmedikleri hakkında bilgi edinerek kariyer hedef davranışlarını düzenleyebilirler (Kerpelman \& Pittman, 2001). Kariyer hedefleriyle ilgili geribildirimler kadar bu geribildirimlerin kaynaklarının da önemli olduğu söylenebilir. Geribildirimlere ilişkin kaynaklar içsel veya dişsal olabilmektedir. İçsel kaynaklardan gelen geri bildirimlerin varlığının bilinmesine rağmen pek çok çalışma dışsal kaynaklara odaklanmaktadır. İçsel geri bildirimler öz-değerlendirme, muhakeme etme ve öz-çözümlemeyi içerir. İçsel geribildirimler, dışsal kaynaklardan gelen geri bildirimlerle uyumlu, tamamlayıcı ya da çelişkili olabilir (Butler \& Winne, 1995). Kariyer hedefi geri bildirimleri de hem dişsal (veliler, öğretmenler ve akranlar gibi) hem de içsel (sezgi ve sosyal karşılaştırmaya dayalı iç duygu ve fikirler gibi) olabilir. Kariyer hedefi geri bildirimi, gençlerin özdüzenleme süreçlerini yönlendirerek ve motive ederek kariyer hedeflerine doğru daha iyi bir ilerleme kaydetmeyi amaçlamaktadır (Hu ve diğerleri, 2017).

Alan yazın incelendiğinde kariyerle ilişkili geri bildirim çalışmalarının çoğunun ya deneysel yöntemleri ya da tek maddelik ölçümleri kullanan çalışmalar olduğu söylenebilir. Örneğin Kerpelman ve Pitman'nın (2001) geribildirimin kariyer kimliğine 
etkisini incelediği çalışma bir deneysel çalışmadır. Paa ve McWhirter'in (2000) yaptıkları çalışmada ise kariyere ilişkin geribildirimlerin yalnızca birer madde (pozitif/negatif geribildirim) ile ölçüldüğü görülmektedir. Alanyazın incelendiğinde kariyer geri bildirimlerini doğrudan ölçen sadece bir ölçeğin (Feedback on Career Progress From on Significant Others Scale -Creed, Wamelink \& Hu, 2015) olduğu görülmektedir. Fakat bu ölçek yalnızca kariyer gelişimi ile ilgili dışsal ve olumsuz geri bildirimlere odaklanmaktadır. $\mathrm{Bu}$ nedenle, geri bildirim yapısının diğer boyutlarını kapsamamaktadır. Bireylerin kariyer hedefleri ile ilgili geribildirimleri ölçmek amacıyla Hu ve diğerleri (2017) tarafından geliştirilen Kariyer Hedefi Geribildirim Ölçeği, alanda dikkate değer olan boşluğu doldurması bakımından önemlidir. Türkçe alanyazın incelendiğinde ise kariyer hedefleri (career goal) ile ilgili sınırlı çalışmalara rastlanılmaktadır. Bu çalışmalarda (Korkmaz, 2018; Korkmaz ve Cenkseven Önder, 2018) kariyer hedeflerinin kariyer uyum yetenekleri açısından önemli olduğu sonucuna ulaşılmıştır. Ancak Türkçe alanyazında kariyer hedefi geribildirimlerini inceleyen bir çalışma bulunmamakla birlikte bahsedilen özellikleri ölçen bir ölçme aracına da rastlanılmamıştır. Gerek Türk toplumunun Amerika gibi bireyci eğilimleri yüksek olan ülkelere göre daha az bireyci eğilimlere sahip olması (Cukur, De Guzman \& Carlo, 2004) gerekse küreselleşmeden dolayı toplumun bir yüzünü bireyci kültürel özelliklere çevirmesi göz önünde bulundurulduğunda, bireyin sağlıklı kariyer gelişim süreci için hem dışsal (sosyal çevre) hem de içsel (kişisel) geribildirimlere ihtiyaç duyabileceği söylenebilir. Türkçe alanyazında kariyerle ilişkili bir geri bildirim ölçeğinin bulunmamasından dolayı kariyer hedefleri hakkındaki geri bildirimleri değerlendirebilen, kısa, çok boyutlu, psikometrik olarak güvenilir olan Kariyer Hedefi Geri Bildirim Ölçeği'nin (KHGÖ) Türkçeye uyarlanması bu bakımdan önemli görülmektedir. Bu nedenle; bu çalışmada $\mathrm{Hu}$ ve diğerlerinin (2017) geliştirmiş olduğu KHGÖ'nün Türkçeye uyarlanması ve ölçeğin Türkçe formunun hem üniversite hem de lise öğrenci örnekleminde geçerlik ve güvenirliğinin incelenmesi amaçlanmıştır.

\section{Yöntem}

Araştırmanın amacına yönelik olarak ölçeğin uyarlama sürecinde yapılan çalışmalar aşağıda sunulmuştur.

\section{Çeviri Çalışması}

İlk önce, ölçeğin geliştirildiği çalışmada sorumlu yazar olarak belirtilen yazardan ölçeğin Türkçeye uyarlanması için izin alınmıştır. Ölçek daha sonra İngilizceye hâkim, psikolojik danışma ve rehberlik alanında iki uzman ve bir İngilizce öğretmeni tarafından Türkçeye çevrilmiştir. Ayrı ayrı olarak yapılan çeviriler daha sonra bir araya getirilerek kariyer danışmanlığı alanında uzman ve İngilizceye hâkim iki öğretim üyesine incelettirilmiştir. Kapsam geçerliğini (content validity) sağlamak için uzmanların değerlendirmeleri Davis tekniği ile incelenmiştir. Bu teknikte maddeler uygun, madde hafifçe gözden geçirilmeli, madde ciddi olarak gözden geçirilmeli ve madde uygun değil şeklinde derecelendirilmektedir. Uzmanların, maddelerin en az \%80'i için uygun veya madde hafifçe gözden geçirilmeli şeklinde değerlendirmeleri kapsam geçerliğini sağlamak için yeterli kabul edilmektedir (Karakoç ve Dönmez, 2014). İnceleme sonunda uzmanlar maddelerin \%60'1 için uygun, \%40'1 için madde hafifçe gözden geçirilmeli şeklinde görüş belirtmişlerdir. Bu sonuçlara göre ölçeğin 
Türkçe formunun kapsam geçerliğini sağladığı söylenebilir. Uygulamadan önce ölçeğin Türkçe dil bilgisi ve yazımı açısından bir Türk dili uzmanından görüş alınmış ve gerekli değişiklikler yapılarak ölçeğe son hali verilmiştir. Ölçeğin dilsel eş değerliğini belirlemek için analiz yapılmış, yapılan analiz sonuçları bulgularda sunulmuştur.

\section{Çalışma Grubu}

$\mathrm{Bu}$ araştırma; Güneydoğu Anadolu Bölgesinde yer alan bir ildeki, bir üniversite ile üç lise ve Akdeniz Bölgesinde yer alan bir ildeki, bir üniversite ile iki lisede gerçekleştirilmiştir. Araştırmanın çalışma grubunu üniversiteye devam eden 199 erkek, $326 \mathrm{k1z}$ öğrenci olmak üzere toplam 525 üniversite öğrencisi, liseye devam eden 250 erkek ve $302 \mathrm{k} 1 \mathrm{z}$ öğrenci olmak üzere toplam 552 lise öğrencisi oluşturmaktadır. Araştırmaya katılan toplam öğrenci sayısı 1.077'dir. Araştırmaya katılan lise öğrencilerinin \%89'u (N=491) kendini orta düzeyde sosyo-ekonomik düzeye sahip görürken \%8'i (N=45) düşük, \%3'ü ( $N=16)$ ise kendini yüksek sosyo-ekonomik düzeye sahip algılamaktadır. Üniversite öğrencilerinin ise \%96's1 $(\mathrm{N}=503)$ kendini orta düzeyde sosyo-ekonomik düzeye sahip görürken \%3'ü $(N=16)$ düşük, \%1'i $(N=6)$ ise kendini yüksek sosyo-ekonomik düzeye sahip algılamaktadır. Üniversite öğrencilerinin yaşları 17 ile 31, lise öğrencilerinin yaşları ise 16 ile 18 arasında değişmektedir. Ölçeğin üniversite grubunda faktör yapısını incelemek için 306 üniversite öğrencisi, lise grubunda incelemek için de 331 lise öğrencisi olmak üzere toplam 637 kişi; test-tekrar test güvenirlik analizi için 51 üniversite öğrencisi, 98 lise öğrencisi olmak üzere toplam 149 kişi; ölçeğin uyum geçerliği için 168 üniversite öğrencisi, 115 lise öğrencisi olmak üzere toplam 283 kişi; ölçeğin dilsel geçerliği için 8 lise öğrencisi, 15 İngilizce öğretmeni olmak üzere toplam 23 kişiye ait veriler kullanılmıştır.

\section{Veri Toplama Araçları}

Araştırmada Kariyer Hedefi Geribildirim Ölçeği (KHGÖ), Kariyer Stresi Ölçeği (KSÖ) ve Genel Öz-Yeterlik Ölçeği'nden (GÖYÖ) oluşan ölçme bataryası kullanılmıştır.

Kariyer Hedefi Geribildirim Ölçeği (KHGÖ). Hu ve diğerleri (2017) tarafından geliştirilen ölçeğin özgün formunda 24 madde yer almaktadır. Ölçekte, bireyin kariyer hedeflerine yönelik yer alan geribildirim cümleleri "Kesinlikle Katılmıyorum" ile “ Kesinlikle Katıliyorum” şeklinde 5'li Likert maddeleri olarak puanlanmaktadır. Ölçekteki olası puanlar 24 ile 120 arasında değişmektedir. Ölçek maddelerinin 22'si olumsuz geribildirim cümlelerinden oluşmaktadır. Ölçekte yalnızca 2 madde olumlu geribildirimi içerdiğinden dolayı tersten puanlanmaktadır. Ölçekten alınan yüksek puan bireyin kariyer hedefleriyle uyumlu yönde davranmadığını bildirmektedir. Orijinal ölçekte yapılan açımlayıcı faktör analizi sonucunda altı faktörlü ve toplam varyansın \%64'ünü açıklayan bir yapı elde edilmiştir. Ölçek; "İçsel-Nasıl Geliştireceğini Bilme”, "Dışsal-Nasıl Geliştireceğini Bilme”, "İçsel-İlerlemede Olma", "Dışsal-İlerlemede Olma", "İçsel-Hedef Uygunluğu” ve "Dişsal-Hedef Uygunluğu" şeklinde isimlendirilen boyutlardan oluşmaktadır. Orijinal formda ölçeğin yap1 geçerliliğini test etmek için yapılan doğrulayıcı faktör analizi sonucunda, orijinal yapının haricinde birden fazla yapının (olası yapılar) da test edildiği görülmüştür. Farklı yapıların da uyum değerlerini karşıladığı ve bu yapıların da kullanılabileceği çalışmada ifade edilmiştir. Ölçeğin özgün formuna ilişkin yayınlanan makalede, aracın 
araştırmacının tercihine göre istenildiği gibi kullanılabileceği belirtilmiştir. $\mathrm{Bu}$ çalışmada açımlayıcı faktör analizinde ortaya çıkan ve toplam ölçeğin \%64'ünü açıklayan orijinal yapının test edilmesi amaçlanmıştır.

Kariyer Hedefi Geribildirim Ölçeği (KHGÖ) özgün formu için hesaplanan iç tutarlık güvenirlik katsayısı tüm ölçek için .94, hedef uygunluğu alt boyutu için .89, nasıl geliştirileceğini bilme alt boyutu için .93 ve ilerlemede olma alt boyutu için .91 bulunmuştur. Madde-toplam korelasyonları altı faktörlü yapı için .31 ile .67 arasında değişiklik göstermiştir. KHGÖ’nün uyum geçerliği için yapılan analizde kariyer gelişimine ilişkin yapılan olumsuz geribildirimle tüm ölçek arasında orta düzeyde pozitif ( $r=.48, p<.01)$, kariyerle ilişkili stresle yüksek düzeyde pozitif $(r=.61, p<.01)$ ve öz-yeterlikle orta düzeyde negatif $(r=-.44, p<.01)$ ilişki bulunmuştur.

Kariyer Stresi Ölçeği (KSÖ). Ölçek, üniversite öğrencilerinin kariyerle ilgili stres kaynaklarını ve zorlanmalarını ölçmek için Choi ve diğerleri (2011) tarafından geliştirilmiş ve Özden \& Sertel-Berk (2017) tarafından Türkçeye uyarlanmıştır. Ölçekte 5'li Likert tipte (1=Hiç Katılmıyorum, 5=Tamamen Katılıyorum) 20 madde yer almaktadır. Ölçekten alınan yüksek puanlar yüksek düzeyde kariyer stresine işaret etmektedir. Araştırma, yaşları 17-68 arasında değişen 425 üniversite öğrencisi üzerinde gerçekleştirilmiştir. Ölçeğin Türkçe formunun iç tutarlık katsayısı .94, madde-toplam korelasyonları ise $.44-.80$ arasında hesaplanmıştır. Ölçeğin test-tekrar test güvenirlik katsayısı ise .81'dir. Ölçek "Kariyer Belirsizliği ve Bilgi Eksikliği”, "Dışsal Çatışma" ve "İş Bulma Baskısı" olarak tanımlanan ve toplam varyansın \%64.7'sini açıklayan 3 faktörden oluşmaktadır. Bu çalışma için ölçeğin Cronbach Alpha güvenirlik katsayısı üniversite öğrencileri veri seti için .91, lise öğrencileri veri seti için .94 olarak bulunmuştur.

Genel Öz Yeterlik Ölçeği (GÖYÖ). Schwarzer \& Jerusalem (1995) tarafından bireylerin stresli yaşantılarla başa çıkabilme ve stresli yaşantılara uyum sağlayabilme becerilerine yönelik algılarını belirlemek amacıyla geliştirilen ölçeğin Türkçeye uyarlaması Aypay (2010) tarafından yapılmıştır. Ölçek, 4'lü Likert tipte (1=Tamamen Yanlış, 4= Tamamen Doğru) 10 maddeden oluşmaktadır. Ölçekten alınan yüksek puan bireyin genel öz yeterliğinin yüksek olduğu anlamına gelmektedir. Ölçek, toplam varyansın \%47'sini açıklayan, "çaba ve direnç" ve "yetenek ve güven” isimden oluşan iki alt ölçekten oluşmaktadır. Güvenirlik analizleri sonucunda birinci faktör için. 79, ikinci faktör için .63 ve ölçeğin tamamı için .83 iç tutarlık katsayısı hesaplanmıştır. Ölçeğin test-tekrar test güvenirliği ise .80 olarak bulunmuştur. Bu çalışma için ölçeğin Cronbach Alpha güvenirlik katsayısı üniversite öğrencileri veri seti için .86, lise öğrencileri veri seti için .89 olarak bulunmuştur.

\section{İșlem}

Uygulamalara başlanmadan önce kurumların yöneticileri ve ders öğretmenlerinden uygulama yapabilmek için izin alınmıştır. Uygulamalar planlanan saatlerde, araştırmacılar tarafından sınıf ortamında gönüllülük esasına dayalı olarak gerçekleştirilmiştir. Ölçek bataryasının tamamlanması 10-15 dakika arasında sürmüştür. 567 üniversite öğrencisi, 583 lise öğrencisi olmak üzere toplam 1.150 öğrenci ölçek bataryasını doldurmuşlardır. Ancak ölçek bataryasında boş maddeler olup olmadığı veya maddelerin özensiz, rastgele yanıtlanıp yanıtlanmadı̆̆ı incelenmiş ve \% 5 'in 
üzerinde eksik verisi olan ya da ölçek bataryasının uygunsuz doldurulduğu belirlenen toplam 73 üniversite ve lise öğrencisine ait veriler veri setinden çıkarılmıştır. \%5'in altında eksik veri olan öğrenci veri setlerinde kayıp veri (missing value) analizi yapılmıştır. Yapılan analizlerde kayıp verilerin rastlantısal dağıldığı görüldügüünden dolayı kayıp veriler serinin ortalaması alınarak tamamlanmıştır. Verilere ait uç değer olup olmadığı verilere ait kutu grafiği (boxplot) ve $\mathrm{z}$ puanları incelenerek değerlendirilmiştir. $Z$ puanı +3 'ten büyük ya da -3 'ten küçük olan veriler ile kutu grafiğinde kutu içinde yer almayan veriler uç değer olarak kabul edilmiştir ve veri setinden 43 veri (33 üniversite, 10 lise) çıkarılmıştır (Çokluk, Şekercioğlu ve Büyüköztürk, 2016). Yapısal eşitlik modeli gibi yapılarda çok değişkenli normalliğin incelenmesi ön şartı bulunmaktadır (Seçer, 2017). Verilerin çok değişkenli normalliği ve doğrusallığı saçılma diyagramı matrisi (scatter plot matix) ile incelenmiştir. İncelenen matrislerde yer alan dağılımların elips şeklinde olması normallik ve doğrusallığın sağlandığı anlamına gelmektedir (Çokluk, Şekercioğlu ve Büyüköztürk, 2016). Verilere ait saçılma diyagramı incelenmiş, dağılımların elips şeklinde yapılar olduğu görülmüştür. Ayrıca verilerin çarpıklık (skewness) ve basıklık (kurtosis) değerleri incelenmiştir. Değerlerin $+/-1$ arasında olduğu ve normal dağılıma sahip olduğu söylenebilir (Seçer, 2017).

\section{Verilerin Analizi}

Ölçeğin uyum geçerliği, madde ayırt ediciliği, test-tekrar test güvenirlik analizi ve dilsel eş değerlik için Pearson Momentler Çarpımı korelasyon analizi kullanılmıştır. Ölçeğin iç tutarlık güvenirliği için Cronbach Alpha katsayıları hesaplanmıştır. Yapı geçerliği için doğrulayıcı faktör analizi yapılmıştır. Ölçeğe ait modelin incelenmesinde RMSEA, CFI, GFI, TLI, Ki kare $\left(\chi^{2}\right)$ ve serbestlik derecesi (sd) değerleri kullanılmıştır. Analizlerin yapılmasında istatistik paket programlarından SPSS 25 ve AMOS 22 kullanılmıştır.

\section{Bulgular}

Ölçeğin uyarlama çalışması kapsamında geçerlik ve güvenirliğine yönelik bulgular aşağıda verilmiştir. Öncelikle uyarlanan ölçeğin dil geçerliği bulguları, yapı geçerliğini test etmek amacıyla yapılan doğrulayıcı faktör analizi bulguları, uyum geçerliği bulguları ve madde analizi bulgularına yer verilmiştir. Daha sonra güvenirliğe yönelik olarak güvenirlik katsayısı ve test - tekrar test güvenirliği bulguları hakkında bilgi verilmiştir.

\section{Kariyer Hedefi Geribildirim Ölçeğinin Geçerliğine İlişkin Bulgular}

Dil geçerliğine ilişkin bulgular. Ölçeğin dilsel eşdeğerliğini belirlemek için 15 İngilizce öğretmeni ve dil sınıfında öğrenim gören 8 lise öğrencisine bir hafta arayla ölçeğin İngilizce ve Türkçe formları uygulanmıştır. Ölçek formlarının toplam puanları arasında anlamlı, pozitif ve yüksek düzeyde $(r=.81, p<.001)$ korelasyon hesaplanmıştır. Hesaplanan korelasyon değerinin .70 ve üzerinde olması, dilsel eşdeğerliğin sağlandığını göstermektedir (Seçer, 2015).

Doğrulayıcı faktör analizine ilişkin bulgular. Çalışmada kullanılan uyum indekslerinden olan $\chi^{2} / \mathrm{sd}$ indeksi genel modelin uyumunu değerlendirmek için 
kullanılır. Bu oranın bazı yazarlara göre 5'ten küçük, bazı yazarlara göre 3'ten küçük olması modelin uyumunun kabul edilebilir olduğu sonucunu vermektedir (Kline, 2005; Meydan \& Şeşen, 2015; Sümer, 2000). Değerlerin 0 ile 2 arasında olması ise mükemmel uyumu göstermektedir (Seçer, 2015; Tabachnick \& Fidell, 2001). Kullanılan bir diğer uyum indeksi RMSEA'nın .05 ve daha düşük olması mükemmel uyuma işaret etmektedir (Brown, 2006; Jöreskog \& Sörbom, 1993; Raykov \& Marcoulides, 2008; Schumacker \& Lomax, 1996). GFI ve CFI'nın .90 ve üzerinde olması iyi uyum değerine sahip olduğunu göstermektedir (Hu \& Bentler, 1999; Kelloway, 1989; Tabachnick \& Fidell, 2001). NNFI olarak da isimlendirilen TLI değeri bazı kaynaklar ve yazılımlarda farklı isimlendirilebilmektedir. AMOS yazılımında NNFI yerine TLI terimi kullanılmaktadır (Seçer, 2015). Bu çalışmada yapılan analizler AMOS ile gerçekleştirildiğinden dolayı bulgularda TLI terimi kullanılmıştır. TLI değerinin 90 ve üzerinde olması modelin iyi uyum gösterdiğine işaret etmektedir (Tabachnick \& Fidell, 2001).

Ölçeğin altı faktörlü, 24 maddeden oluşan özgün yapısını test etmek için üniversite ve lise öğrenci gruplarında ayrı ayrı doğrulayıcı faktör analizi yapılmıştır. Üniversite ve lise öğrencilerine ait veriler üzerinde gerçekleştirilen doğrulayıcı faktör analizinde hiçbir sınırlama yapılmadan modelin uyum indeksleri incelenmiştir. Üniversite öğrencilerinin veri grubuna yapılan doğrulayıcı faktör analizi sonucunda hesaplanan uyum indeksleri incelendiğinde; $\chi^{2}=451.13, \mathrm{sd}=246, \chi^{2} / \mathrm{sd}=1.83$, RMSEA=.05, CFI=.92, GFI=.90, TLI=.91 değerlerinin modelin uyum değerlerini karşıladığ1 söylenebilir. Ölçekteki maddelerin faktör yük değerlerinin .45 ile .82 arasında değiştiği görülmektedir. Faktör yük değerlerinin .45 ve üzerinde olması iyi bir ölçüme işaret etmektedir (Büyüköztürk, 2014). Analize ilişkin bağlantı diyagramı standart katsayıları Şekil 1'de verilmiştir. 
Şekil 1. Üniversite Öğrencileri İçin KHGÖ Doğrulayıcı Faktör Analizi Sonuçları

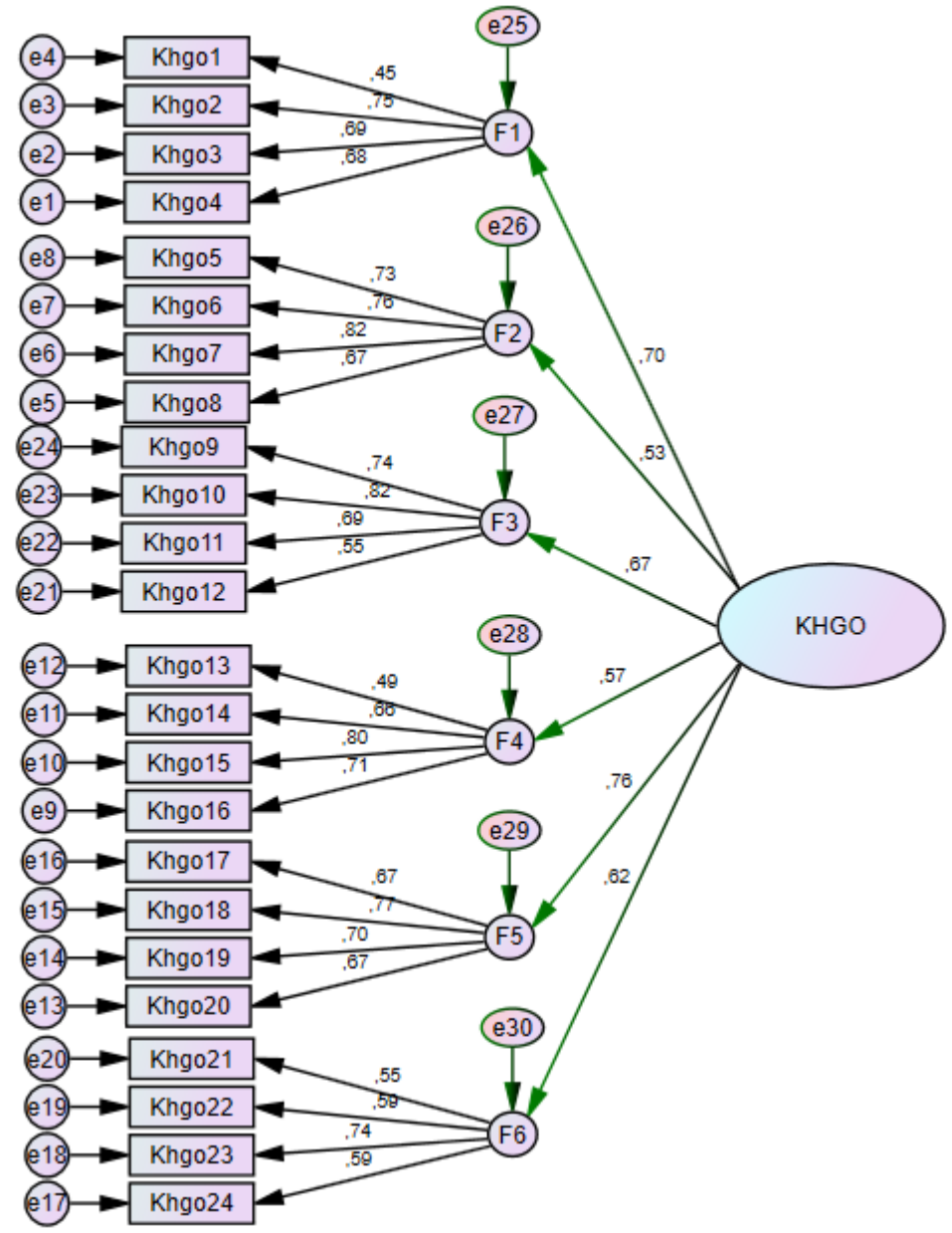

(F1: İçsel - Nasıl Geliştireceğini Bilme, F2: Dışsal - Nasıl Geliştireceğini Bilme, F3: Dışsal - İlerlemede Olma, F4: Dişsal - Hedef Uygunluğu, F5: İçsel İlerlemede Olma, F6: İçsel - Hedef Uygunluğu)

Lise öğrencilerine ait veri grubuna yapılan doğrulayıcı faktör analizi sonucunda hesaplanan uyum indeksleri incelendiğinde; $\chi^{2}=395.78, \quad \mathrm{sd}=237, \quad \chi^{2} / \mathrm{sd}=1.67$, RMSEA=.05, CFI=.93, GFI=.91, TLI=.92 değerlerinin modelin uyum değerlerini karşıladığı söylenebilir. Ölçekteki maddelerin faktör yük değerlerinin .37 ile .77 arasında değiştiği görülmektedir. Analize ilişkin bağlantı diyagramı standart katsayıları Şekil 2'de verilmiştir. 
Şekil 2. Lise Öğrencileri İçin KHGÖ Doğrulayıcı Faktör Analizi Sonuçları

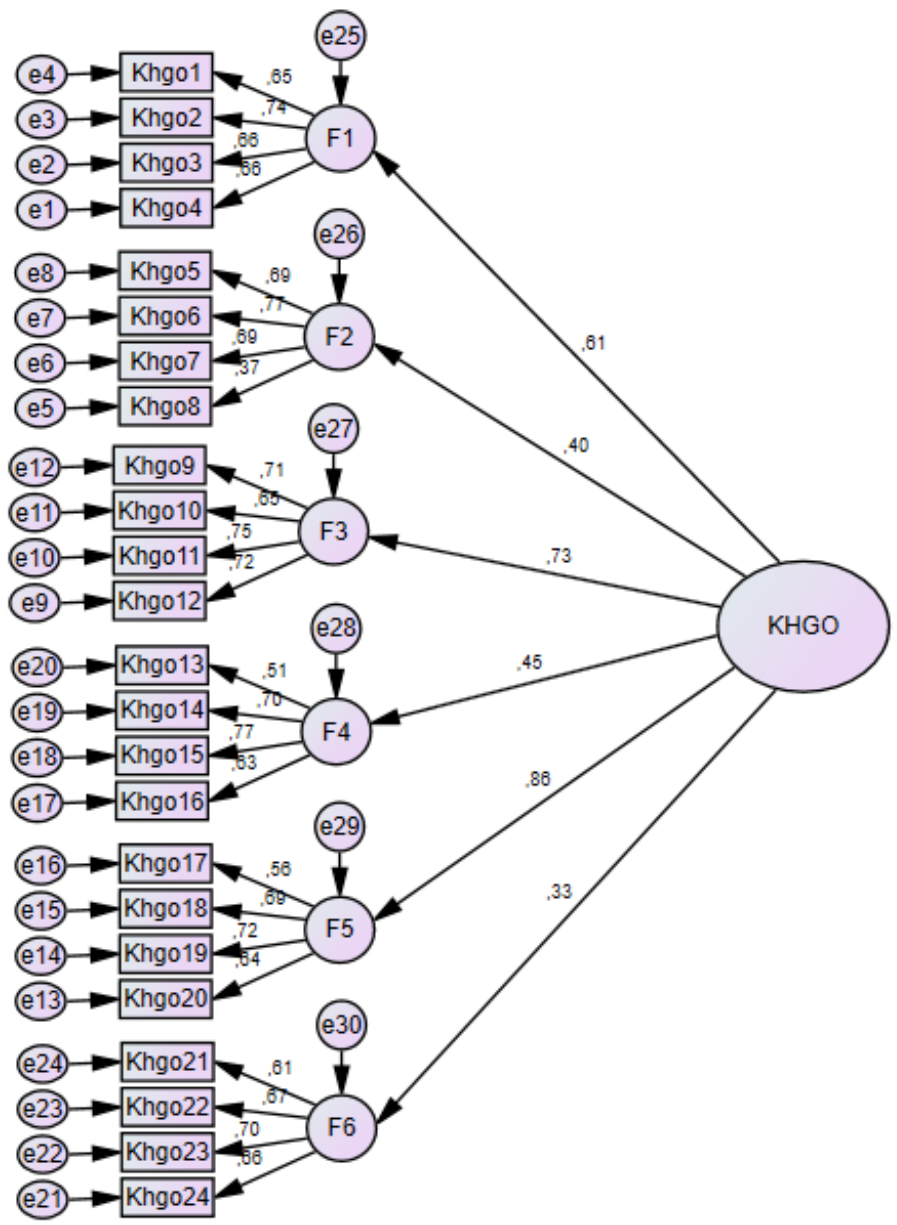

(F1: İçsel - Nasıl Geliştireceğini Bilme, F2: D1şsal - Nasıl Geliştireceğini Bilme, F3: Dişsal -İlerlemede Olma, F4: Dışsal - Hedef Uygunluğu, F5: İçsel İlerlemede Olma, F6: İçsel - Hedef Uygunluğu)

Uyum geçerliğine ilişkin bulgular. Ölçeğin uyum geçerliğini belirlemek için yapılan korelasyon analizlerine göre üniversite öğrencilerinin Kariyer Hedefi Geribildirim Ölçeğinden aldıkları puanlar ile Kariyer Stresi Ölçeğinden aldıkları puanlar arasında anlaml, pozitif ve yüksek düzeyde $(r=.71, p<.001)$ ve Genel Öz Yeterlik Ölçeğinden aldıkları puanlar arasında anlamlı, negatif ve orta düzeyde $(r=$ .41, $p<.001)$ ilişsiler elde edilmiştir. Lise öğrencilerinde de benzer şekilde, Kariyer Hedefi Geribildirim Ölçeğinden alınan puanlar ile Kariyer Stresi Ölçeğinden alınan puanlar arasında anlaml, pozitif ve yüksek düzeyde $(r=.72, p<.001)$ ve Genel Öz Yeterlik Ölçeğinden alınan puanlar arasında anlamlı, negatif ve orta düzeyde $(r=-.48$, $p<.001)$ ilişkiler elde edilmiştir.

\section{Kariyer Hedefi Geribildirim Ölçeğinin Güvenirliğine İlişkin Bulgular}

Ölçeğin güvenirliğine ilişkin olarak Cronbach Alpha iç tutarlılık katsayısı hesaplanmış ve test-tekrar test korelasyonlarına bakılmıştır. Tablo 1'de görüldügü gibi üniversite öğrencilerine ait veri grubunda hesaplanan Cronbach Alpha iç tutarlılık katsayısı ölçeğin alt boyutlarında sırasıyla .73, .83, .79, .75, .80 ve .71 olarak hesaplanırken ölçeğin tamamı için .88 olarak bulunmuştur. Lise öğrencilerine ait veri 
grubunda ise Cronbach Alpha iç tutarlılık katsayısı alt boyutlarda sırasıyla .77, .72, .80, $.74, .74$ ve .76 olarak hesaplanırken ölçeğin tamamı için bu katsayı .85 olarak bulunmuştur.

Tablo 1

KHGÖ Toplam ve Alt Ölçekler İçin İç Tutarlık Değerleri

\begin{tabular}{lcc}
\hline Toplam Ölçek ve Alt Ölçekler & Lise & Üniversite \\
\hline İçsel - Nasıl geliştireceğini bilme & .77 & .73 \\
Dışsal - Nasıl geliştireceğini bilme & .72 & .83 \\
Dışsal - İlerlemede olma & .80 & .79 \\
Dışsal - Hedef uygunluğu & .74 & .75 \\
İçsel - İlerlemede olma & .74 & .80 \\
İçsel - Hedef uygunluğu & .76 & .71 \\
KHGÖ toplam puan & .85 & .88 \\
\hline
\end{tabular}

Ölçeğin test-tekrar test güvenirliği için dört hafta arayla uygulanması sonucu elde edilen toplam puanlar arasındaki korelasyonlar üniversite öğrencilerinde .77 $(p<.001)$, lise öğrencilerinde $.73(p<.001)$ düzeyinde hesaplanmıştır. Ölçeğin ilk ve son uygulamalarından sonra alt boyutlara ilişkin hesaplanan toplamlar arasındaki korelasyon katsayıları incelenmiştir. Üniversite öğrencilerinde, ölçeğin alt boyutlarının ilk ve son puan toplamları arasındaki korelasyon katsayılarının .56 ile .73 arasında anlamlı $(p<.001)$ olarak değiştiği görülmüş̧ür. Lise öğrencilerinde ise alt boyutlara ilişkin tekrar ölçümlerin boyutlar arasındaki korelasyon katsayılarının .52 ile .60 arasında ve anlamlı $(p<.001)$ olarak değiştiği görülmüştür.

Kariyer Hedefi Geribildirim Ölçeğinin madde ayırıcılığını incelemek için madde analizi yapılmıştır. Üniversite öğrencilerine ait veri grubunda madde-toplam korelasyonlarının .36 ile .62; lise öğrencilerine ait veri grubunda madde-toplam korelasyonlarının .31 ile .56 arasında değiştiği bulunmuştur. Ölçek geliştirme ve uyarlama süreçlerinde, ölçülecek özelliği ayırt etme açısından madde-toplam korelasyonunun en az .30 ve üzerinde olması (Büyüköztürk, 2014) göz önüne alındığında maddelerin ölçülecek özellikleri ayırt edebildiği söylenebilir.

\section{Sonuç ve Tartışma}

Bu çalışmanın amacı Hu ve diğerlerinin (2017) geliştirmiş olduğu KHGÖ’nün Türkçeye uyarlanması ve ölçeğin Türkçe formunun hem üniversite hem de lise öğrenci örnekleminde geçerlik ve güvenirliğinin incelenmesidir.

Ölçeğin çevirisini iki dile de hâkim iki alan uzmanı ve bir İngilizce öğretmeni gerçekleştirmiş, çevirisi yapılan ifadeler iki akademisyen ve bir Türk dili uzmanı tarafından incelenmiştir. Türkçe ve orijinal formlar 15 İngilizce öğretmeni ve 8 lise öğrencisine uygulanmış ve korelasyon .81 bulunmuştur. KHGÖ’nün yapı geçerliği doğrulayıcı faktör analizi ile incelenmiştir. Ölçeğin DFA sonuçlarında ortaya çıkan uyum değerlerinin uyum indeksi sınırları göz önüne alındığında, ölçeğin faktör yapısına ilişkin oluşturulan modelin orijinal yapı ile iyi uyum gösterdiği söylenebilir. Buna göre 
ölçeğin orijinal altı faktörlü yapısının Türk örneklem için hem lise öğrencileri $\left(\chi^{2}=\right.$ 395.78, $\left.\mathrm{sd}=237, \chi^{2} / \mathrm{sd}=1.67, \mathrm{RMSEA}=.05, \mathrm{CFI}=.93, \mathrm{GFI}=.91, \mathrm{TLI}=.92\right)$ hem de üniversite öğrencileri $\left(\chi^{2}=451.13, \mathrm{sd}=246, \chi^{2} / \mathrm{sd}=1.83, \quad \mathrm{RMSEA}=.05, \quad \mathrm{CFI}=.92\right.$, $\mathrm{GFI}=.90, \mathrm{TLI}=.91)$ üzerinde korunduğu söylenebilir. Ölçekte "İlerlemede Olma", "Nas1 Geliştireceğini Bilme" ve "Hedef Uygunluğu" şeklinde üç farklı boyut bulunmaktadır. "İlerlemede Olma" bireyin kariyer hedefleriyle ilgili gösterdiği ilerlemeyi, motivasyonu ve çalışma durumunu yansıtmaktadır. "Nasıl Geliştireceğini Bilme" bireyin kariyer hedeflerine ulaşmak için yapması gerekenler hakkındaki sahip olduğu bilgi ve aldığı tavsiyelerin durumunu ifade etmektedir. "Hedef Uygunluğu" ise belirlenen kariyer hedeflerinin birey için uygunluğunu yansıtmaktadır. Bu boyutlar ayrıca bireyin kendisi (içsel) ve çevresi (dışsal) tarafından olmak üzere iki farklı kaynaktan gelen bildirimlerle birlikte "İçsel-İlerlemede Olma" ve "Dışsal-İlerlemede Olma" şeklindeki gibi altı alt boyuta ayrılmaktadır.

Uyum geçerliği çalışmasında KHGÖ ile Kariyer Stresi Ölçeği ile Genel ÖzYeterlik ölçekleri arasında korelasyonlar hesaplanmıştır. KHGÖ’nün kariyer stresi ile pozitif ilişkili, genel öz-yeterlik ile negatif ilişkili olduğu görülmüştür. Orijinal ölçeğin geliştirildiği çalışmada da benzer sonuçların bulunduğu görülmektedir. Anılan çalışmada kariyerle ilişkili stres arasında pozitif, kariyer öz-yeterliği arasında ise negatif bir ilişki bulunmuştur. Bu sonuçlar, kariyerle ilgili geribildirimlerin bireyin bilişsel ve duyuşsal çıktıları ile ilişkili olduğunu ortaya koymaktadır. Çalışmanın bu sonuçları kariyerle ilgili öz-düzenleme süreçlerinin anlaşılmasında birden fazla kaynağın değerlendirilmede kullanılabileceğini göstermiştir. $\mathrm{Bu}$ korelasyon değerlerine bakıldığında ortaya çıkan sonuç KHGÖ’nün uyum geçerliği için önemli bir sonuç olarak yorumlanabilir. Yapı, uyum ve dilsel geçerliğe ilişkin bulgulara bakıldığında elde edilen bu sonuçlara göre KHGÖ’nün Türkçe formunun geçerlik kriterlerini sağladı̆̆ söylenebilir.

Ölçeğin orijinal formunun tüm ölçek için Cronbach Alpha iç tutarlık katsayısı .95, alt boyutların iç tutarlık güvenirlik katsayısı ise .78 ile .94 aralığında hesaplanmıştır (Hu ve diğerleri, 2017). Uyarlaması yapılan ölçeğin Cronbach Alpha iç tutarlık katsayısı ise üniversite öğrencileri için .88 , lise öğrencileri için ise .85 bulunmuştur. Ölçeğin Türkçe formunun alt boyutlarının iç tutarlık güvenirlik katsayıları ise .71 ile .83 arasında değişmektedir. Cronbach Alpha iç tutarlık katsayılarının .70 ve üzerinde olması, ölçeğe ilişkin hesaplanan puanların güvenirliğinin yeterli olduğuna işaret etmektedir (Landis \& Koch, 1977; Robinson, Shaver \& Wrightsman, 1991).

KHGÖ’nün hem alt boyutlar hem de toplam puan açısından iç tutarlılık ve testtekrar test güvenirliğine sahip olduğu belirlenmiştir. KHGÖ’nün geçerlik ve güvenirlik sonuçlarına göre ölçeğin Türkçe formunun hem üniversite hem de lise öğrencilerinde kullanıma uygun olduğu söylenebilir.

\section{Öneriler}

Türkçeye uyarlanan bu ölçeğin, lise ve üniversite öğrencilerinin kariyer gelişim süreçlerinde geribildirimin önemini araştıran çalışmaların yapılmasında kolaylık sağlayacağı söylenebilir. Araştırmacılar kariyer geribildiriminin ergenler ve gençler üzerinde etkilerini araştırmak için bu ölçeği kullanabilirler. Ayrıca kariyer hedeflerine ilişkin geribildirimlerin bilişsel, duygusal, davranışsal (motivasyon, öz-düzenleme, 
yaşam amaçları, kariyer uyum yetenekleri, öz-yeterlik, sonuç beklentileri gibi) kavramlarla ilişkilerinin anlaşılmasının da önemli olduğu söylenebilir.

Ölçek aynı zamanda kariyer danışmanlığında ya da kariyer hedefleri ile ilgili yapılan eğitim programlarının etkililiğini ölçmede kullanılabilir. Uygun kariyer hedefleri belirleme, hedefleri düzenleme, daha da fazla gelişim gösterebilmek için stratejileri belirlemeye ihtiyacı olan öğrencilerin belirlenmesi için bir tarama aracı olarak da kullanılabilir. Liselerde çalışan psikolojik danışmanlar mesleki rehberlik çalışmaları kapsamında bu ölçeği kullanarak kariyer hedefleri ile ilgili tutarsızlık yaşayan öğrencileri tespit edebilir, ölçeğin aynı alt boyutlarında benzer tutarsızlıklara sahip olan öğrencilere yönelik uygun programlar hazırlayabilir ve hazırlanan programların etkililiği test edilebilir. Üniversitelerin psikolojik danışma veya kariyer merkezlerinde çalışan uzmanlar, kariyerleri ile ilgili danışma alma talebinde bulunan danışanların kariyer hedefleriyle ilgili yönde hareket edip edemediklerini tespit etmek ve danışanın uygun kariyer yönü çizmesine yardımcı olmak için bu ölçeği kullanabilirler.

Uyarlanan bu ölçek, bireylerin kariyerleriyle ilgili belirledikleri hedeflerle ilişkili şekilde hareket edip etmediklerini ölçmeye çalışmaktadır. Ancak bireylerin ne tür bir kariyer hedefi ya da hedefleri belirlediği ve hangi kariyer hedefleriyle tutarsiz hareket ettiği bilinememektedir. $\mathrm{Bu}$ nedenle bireylerin ne tür kariyer hedefleri belirlediğini ölçen bir ölçeğe de ayrıca ihtiyaç duyulduğu göz ardı edilmemelidir. Çünkü bireylerin belirledikleri amaçlarının kendisi ya da kendisi dışındaki faktörlerin etkisiyle oluşturulması (içsel ve dışsal faktörler), bireylerin kariyer hedeflerine yönelik motivasyonunu ve bağlılığını da etkileyebilir. Dolayısıyla anılan şekilde geliştirilebilecek bir ölçek ile KHGÖ'nün birlikte kullanılması, bireylerin kariyer hedeflerinin aydınlatılmasına yönelik güçlü bir ışık tutabilir.

$\mathrm{Bu}$ araştırmanın bazı sınırlılıkları vardır. Araştırma; iki farklı bölgede yer alan iki ilde, çoğunluğu orta sosyo-ekonomik düzeye sahip katılımcılar üzerinde gerçekleştirilmiştir. Araştırmanın dış geçerliğini sağlamak amacıyla farklı bölgelerden katılımcılarla ölçeğin geçerlik ve güvenirliği yeniden test edilebilir. Ayrıca farklı sosyoekonomik gruplarda ölçeğin geçerlik ve güvenirliği yeniden gözden geçirilebilir. 


\section{Summary}

Purpose and Significance: Career is a concept that expresses the individual's lifelong pursuits and the role they play throughout their lives. Career setting and decisionmaking processes which are common in high school or university years are an issue that should be emphasized for the rest of life (Sharf, 2017). According to the goal orientation and self-regulation approach, people can actively set their own goals and can regulate their behaviors in an aware or not aware way to reach these goals (Bandura, 1991; Latham \& Locke, 1991). Career goal feedback provides information about the suitability of the career goal, the adequacy of the goal-directed progression and what changes need to be made to achieve the goals (Hu, Creed, \& Hood, 2017). Adolescents and young adults who are in their career setting period can arrange their career goal behavior by getting feedback about the general situation of their career goals and whether they act consistently with these goals (Kerpelman \& Pittman, 2001). Due to the lack of a feedback scale for the Turkish language, the adaptation of the short, multidimensional, psychometrically reliable Career Goal Feedback Scale, which can assess the feedback on career goals, to the Turkish language, is also significant. Therefore; in this study, it was aimed to adapt CGFS, which was developed, by $\mathrm{Hu}$, Creed and Hood (2017) to Turkish and examine the validity and reliability of it's in both university and high school student sample.

Methods: Permission for the adaptation of the scale has been obtained and translated into English with the help of language and field experts. The validity and reliability studies of the scale were carried out in one university and three high school located in a city in the Southeastern Anatolian Region and one university and two high school located in a city in the Mediterranean Region. The research group of the study consisted of 525 university students attending to the university (199 male, 326 female) and 552 high school students (250 male, 302 female) attending to the high school. The measurement was composed of Career Goal Feedback Scale, Career Stress Scale and General Self-Efficacy Scale. Pearson's Moments Multiplication correlation analysis was used for the concurrent validity, item discrimination, test-retest reliability and linguistic equivalence of the scale. Cronbach Alpha coefficients were calculated for internal consistency reliability of scale. Confirmatory factor analysis was performed for construct validity. RMSEA, CFI, GFI, TLI, Chi Square $\left(\chi^{2}\right)$ and degree of freedom (df) values were used in the study of scale model. The data was analyzed with SPSS 25 and AMOS 22 statistics programs.

Results: In order to determine the linguistic equivalence of the scale, 15 English teachers and 8 high school students studying in the language class filled English form of the scale first and they filled Turkish form of scale one week later. A significant, positive and high level of correlation was calculated between the total scores of the English and Turkish scale form. In order to test the original structure of the scale consisting of six factors and 24 items, confirmatory factor analysis was performed separately in the university and high school student groups. For the analysis results related to construct validity, it was shown that the model, consisting of 24 items and six dimensions, adapted well for the university students sample $\left(\chi^{2}=451.13, \mathrm{sd}=246\right.$, 
$\left.\chi^{2} / \mathrm{sd}=1.83, \mathrm{RMSEA}=.05, \mathrm{CFI}=.92, \mathrm{GFI}=.90, \mathrm{TLI}=.91\right)$. Similarly, analysis result related to construct validity, it was shown that the model, consisting of 24 items and six dimensions, adapted well for the high school students sample too $\left(\chi^{2}=395.78, \mathrm{sd}=237\right.$, $\chi^{2} / \mathrm{sd}=1.67, \mathrm{RMSEA}=.05, \mathrm{CFI}=.93, \mathrm{GFI}=.91$, TLI=.92). Correlation analyzes were performed to determine the concurrent validity of scale adaptation. In university student samples; significant, positive and high correlation $(r=.71, p<.001)$ between Career Goal Feedback Scale and Career Stress Scale, and significant, negative and medium correlation $(r=-.41, p<.001)$ between General Self-Efficacy Scale scores were obtained. Similarly, in high school student samples; significant, positive and high correlation ( $r=$ $.72, p<.001)$ between Career Goal Feedback Scale and Career Stress Scale, and significant, negative and medium correlation $(r=-.48, p<.001)$ between General SelfEfficacy Scale scores were obtained. The Cronbach Alpha internal consistency coefficient was calculated for the reliability of the scale. As a result of the analysis, Cronbach Alpha internal consistency coefficient between .71 - .88 for university students and $.72-.85$ for high school students was found. The scale was applied at fourweek intervals. The correlations between the total scores obtained test-retest reliability were calculated $.77(p<.001)$ for university students and $.73(p<.001)$ for high school students. Item analysis was conducted to examine the item separability of the Career Goal Feedback Scale. In the data group of university students, item-total correlations were found to change between .36 and .62 , and in the data group of high school students item-total correlations changed between .31 and .56 .

Discussion and Conclusions: This scale, which is adapted to Turkish, can be said to facilitate the studies that investigate the importance of feedback in high school and university students' career development processes. Researchers can use this scale to investigate the effects of career feedback on adolescents and young people. The scale can also be used to measure the effectiveness of training programs for career goals, and career counseling. It can also be used as a screening tool to set appropriate goals, to edit goals and to identify students who need to identify strategies to identify career goals and further develop. 


\section{Kaynakça}

Aypay, A. (2010). The adaptation study of General Self-Efficacy (GSE) Scale to Turkish. Inonu University Journal of the Faculty of Education, 11(2), 113-131.

Bandura, A. (1991). Social cognitive theory of self-regulation. Organizational Behaviour and Human Decision Processes, 50, 248-287.

Brown, T. A. (2006). Confirmatory factor analysis for applied research (1. Bask1.). New York: Guilford Pubications, Inc.

Butler, D. L., \& Winne, P. H. (1995). Feedback and self-regulated learning: A theoretical synthesis. Review of Educational Research, 65, 245-281.

Büyüköztürk, Ş. (2014). Sosyal bilimler için veri analizi el kitabı (20. Baskı.). Ankara: Pegem Akademi.

Choi, B. Y., Park, H. R., Nam, S. K., Lee, J., .., \& Lee, S. M. (2011). The development and initial psychometric evaluation of the Korean Career Stress Inventory for college students. Career Development Quarterly, 59, 559-572.

Creed, P. A., Wamelink, T., \& Hu, S. (2015). Antecedents and consequences to perceived career goalprogress discrepancies. Journal of Vocational Behavior, 87, 43-53.

Cukur, C. S., De Guzman, M. R. T., \& Carlo, G. (2004). Religiosity, values, and horizontal and vertical individualism-collectivism: A study of Turkey, the United States, and the Philippines. The Journal of Social Psychology, 144(6), 613-634.

Çokluk, Ö., Şekercioğlu, G., \& Büyüköztürk, Ş. (2016). Sosyal bilimler için çok değişkenli istatistik SPSS ve LISREL uygulamaları (4. Baskı.). Ankara: Anı Yayıncilik.

Greenhaus, J. H., Callanan, G. A., \& Kaplan, E. (1995). The role of goal setting in career management. International Journal of Career Management, 7(5), 3-12.

Hattie, J., \& Timperley, H. (2007). The power of feedback. Review of Educational Research, 77(1), 81-112. https://doi.org/10.1111/j.1365-2923.2009.03542.x

Hu, L., \& Bentler, P. M. (1999). Cutoff criteria for fit indexes in covariance structure alanysis: Conventional criteria versus new alternatives. Structural Equation Modeling, 6, 1-55.

Hu, S., Creed, P. A., \& Hood, M. (2017). Development and initial validation of a measure to assess career goal feedback. Journal of Psychoeducational Assessment, 35(7), 657-669.

Jöreskog, K. G., \& Sörbom, D. (1993). LISREL 8: Structural equation modeling wit the simplis command language. Lincolnwood: Scientific Software International, Inc.

Karakoç, F. Y., \& Dönmez, L. (2014). Ölçek geliştirme çalışmalarında temel ilkeler. Tip Ĕ̈itimi Dünyası, 40, 39-49.

Kelloway, K. E. (1989). Using LISREL for structural equation modeling: A researcher's guide (Sage.). London.

Kerpelman, J. L., \& Pitmann, J. F. (2001). The instability of possible selves: Identity processes within late adolescents' close peer relationships. Journal of Adolescence, 24, 491-512. 
Kline, R. B. (2005). Principles and practice of structural equation modeling (2. Bask1.). New York: Guilford Pubications, Inc.

Korkmaz, O. (2018). Lise öğrencilerinin kariyer uyum yeteneklerinin sosyo-demografik özellikler açısından karşılaştırılması. 20. Uluslararası Psikolojik Danışma ve Rehberlik Kongresi 25-27 Ekim 2018 içinde (s. 383-384). Canik Kültür Merkezi: Samsun, Türkiye. Erişim adresi: https://2018.pdrkongreleri.org/dosyalar/files/pdr2018_ozetler_kitabi.pdf

Korkmaz, O. \& Cenkseven Önder (2018). Yaşam amaçları ile kariyer uyum yetenekleri arasındaki ilişkinin incelenmesi: Umudun aracılık rolü. 20. Uluslararası Psikolojik Danışma ve Rehberlik Kongresi 25-27 Ekim 2018 içinde (s. 383-384). Canik Kültür Merkezi: Samsun, Türkiye. Erişim adresi: https://2018.pdrkongreleri.org/dosyalar/files/pdr2018_ozetler_kitabi.pdf

Landis, J. R., \& Koch, G. G. (1977). The measurement of observer agreement for categorical data. Biometrics, 33, 159-174.

Locke, E. A., \& Latham, G. P. (2002). Building a practically useful theory of goal setting and task motivation: A 35-year odyssey. American Psychologist, 57(9), 705.

Locke, E. A. \& Latham, G. P. (2006). New directions in goal-setting theory. Current Directions in Psychological Science, 15(5), 265-268.

Meydan, C. H., \& Şeşen, H. (2015). Yapısal eşitlik modellemesi AMOS uygulamaları (2. Bask1.). Ankara: Detay Yayıncılık.

Özden, M. C. (2007) Bireysel Kariyer Yönetimi. İstanbul: Akis Kitap.

Özden, K., \& Sertel-Berk, Ö. (2017). Kariyer Stresi Ölçeği'nin ( KSÖ ) Türkçe 'ye uyarlanması ve psikometrik özelliklerinin sınanması. Psikoloji Çalışmaları Dergisi, 37(1), 35-51.

Paa, H. K. \& McWhirter, E. H. (2000). Perceived influences on high school students' current career expectations. The Career Development Quarterly, 49, 29-49.

Raykov, T., \& Marcoulides, G. (2008). An introduction to applied multivariate analysis (1. Bask1.). New York: Taylor \& Francis, Ltd.

Robinson, J. P., Shaver, P. R., \& Wrightsman, L. S. (1991). Criteria for scale selection and evulation in measure of personality and social psychological attitudes. San Diego: California Academic Press.

Schumacker, R. E., \& Lomax, R. G. (1996). A beginner's guide to structural equation modeling (1. Bask1.). NJ: Lawrence Erlbaum Associates, Inc.

Seçer, İ. (2015). Psikolojik test geliştirme ve uyarlama süreci. Ankara: Anı Yayıncılık.

Seçer, İ. (2017). SPSS ve LISREL ile pratik veri analizi analiz ve raporlaştırma. Ankara: Anı Yayıncilık.

Sharf, R. S. (2017). Kariyer gelişim kuramlarının kariyer danışmasına uygulanması. (F. Bacanlı \& K. Öztemel, Ed.) (1. Bask1.). Ankara: Pegem Akademi. doi:10.14527/9786053185741

Sümer, N. (2000). Yapısal eşitlik modelleri. Türk Psikoloji Yazıları, 3(6), 49-74. 
Schwarzer, R., \& Jerusalem, M. (1995). Generalized self-efficacy scale. Içinde J. Weinman, S. Wright \& M. Johnston (Ed.), Measures in health psychology: A user's portfolio. Causal and control beliefs. UK: NFER-Nelson.

Tabachnick, B. G., \& Fidell, L. S. (2001). Using multivariate statistics (4. Bask1.). MA: Allyn\&Bacon, Inc.

Zajas, J. J., \& Zajas, J. R. (1994). Planning your total career and life portfolio-part 1: A model for management development. Librarian Career Development, 2(3), 0710. 